\title{
Quantitation of Phenolic Compounds Related to Antioxidant and Antiosteoporosis Activities in Ripe and Unripe Maesil (Prunus mume)
}

\author{
Chong Woon Cho $\mathbb{D}^{1},{ }^{1}$ Young Sik Park, ${ }^{2}$ Xi-Tao Yan, ${ }^{3}$ Hyun June Kim, ${ }^{1}$ Young Ho Kim, \\ Kyung Tae Kim, ${ }^{4}$ Chu Van Men $\mathbb{D}^{\mathbb{D}},{ }^{5}$ and Jong Seong Kang $\mathbb{D}^{1}$ \\ ${ }^{1}$ College of Pharmacy, Chungnam National University, Daejeon, Republic of Korea \\ ${ }^{2}$ Graduate School of New Drug Discovery and Development, Chungnam National University, Daejeon, Republic of Korea \\ ${ }^{3}$ School of Chemistry \& Pharmacy, Northwest A \& F University, Xianyang, Shaanxi, China \\ ${ }^{4}$ Division of Bioengineering, Dong-Eui University, Busan, Republic of Korea \\ ${ }^{5}$ Clinical Trial and Bioequivalent Testing Centre, Vietnam Military Medical University, Hanoi, Vietnam
}

Correspondence should be addressed to Chu Van Men; chuvanmen@vmmu.edu.vn and Jong Seong Kang; kangjss@cnu.ac.kr

Received 20 May 2020; Revised 30 July 2020; Accepted 19 August 2020; Published 14 September 2020

Academic Editor: Antimo Di Maro

Copyright (c) 2020 Chong Woon Cho et al. This is an open access article distributed under the Creative Commons Attribution License, which permits unrestricted use, distribution, and reproduction in any medium, provided the original work is properly cited.

\begin{abstract}
The fruits of Prunus mume, maesil (Rosaceae), have been widely used as a valuable source of foods and herbal medicines from ancient times in Northeast Asia. Specially, phenolic compounds of main compounds in maesil were reported to have various activities. This study aims to develop the simultaneous analytical method of nine phenolic compounds in maesil and to evaluate these compound contents in samples during the ripeness. Twenty-one species of samples and nine phenolic compounds were used for this study. In results, compounds $1-9$ contents in unripe fruits were $0.16 \sim 1.81 \mathrm{mg} / \mathrm{g}$. However, these compounds in ripe samples were $0.09 \sim 1.66 \mathrm{mg} / \mathrm{g}$. Compounds 1-9 contents in ripe fruits were generally reduced rather than those in unripe fruits. Otherwise, the contents of compounds $2,5,8$, and 9 in seed part were relatively higher than those in flesh part. In contrast, contents of compounds 1, 3, and 7 in flesh part were relatively higher than those in seed part. Generally, the contents of compounds 1-9 in unripe fruits were higher than those in ripe fruits. However, the contents of compounds 1-9 in each part (seed and fresh) of fruits were different according to species of compounds. It indicates that the selection of harvesting time and process part of fruits as the source of foods and medicines is important.
\end{abstract}

\section{Introduction}

The fruit of Prunus mume Sieb. et Zucc (Rosaceae) is mainly cultivated in Eastern Asian countries including Korea. It is called maesil in Korea, which has been widely used as a valuable source of food such as fermented food, sauce, wine, and juice. Also, the unripe maesil treated by smoking or steaming process is called as ome in Korea, and it has been used as a traditional medicine for the treatment of emetic, tussis, sputum, diarrheal, and pyretic disease for long time [1]. And maesil has been reported to have various biological activities such as antioxidant [2-11], antimicrobial, and antibacterial [12-15], mitogenesis [16], inhibition of growth signals of vascular smooth muscle cells [17], apoptosis [18], anti-inflammatory activity $[19,20]$, anticancer cell $[9,21]$, immune function enhancing, therapeutic activities for cognitive impairments by Alzheimer's disease [22], cytoprotective [23], antidiabetic activity [24], antiobesity activity [25], and antiosteoporosis activity [26, 27].

Phytochemicals in mume fruits have been reported as various kinds of benzaldehyde, benzyl alcohols, flavonoids [10], monoterpene alcohols, benzyl glucoside, monoterpenoids, saturated fatty acids and organic acids, chlorogenic acid derivatives, volatile components' one 
chain-type triterpenes, ursane-type triterpenes, cycloartanetype triterpenes, sterols, and acylated sucroses (muerose $P$, $Q$, and $R$ ) with antioxidants and antiosteoporosis activities $[27,28]$.

Some of these components' contents with various bioactivities in maesil were developed with simultaneous analytical methods using gas chromatography-mass spectroscopy (GC-MS) for volatile organic compounds such as benzaldehyde, 2-hexanal, isolongifololyl acetate, palmitic acid, linalool, butyl acetate, linoleic acid, and squalene [29-31].

In contrast, the simultaneous analytical method for some kinds of compounds such as mumefural using highperformance liquid chromatography (HPLC) and liquid chromatography-mass spectrometry (LC-MS) was reported. In particular, the separation and isolation methods of phenolic compounds such as 4-O-caffeoylquinic acid methyl ester, prunasin, 5-O-caffeoylquinic acid methyl ester, benzyl-O- $\beta$-D-glucopyranoside, and liquiritigenin-7-O- $\beta$-D-glucopyranoside were studied by many researchers $[32,33]$. But, the simultaneous analytical methods for these compounds using HPLC and LC-MS in maesil were nominal. In particular, the analytical method to analyze the active compounds with antiosteoporosis such as neochlorogenic acid, benzyl$\beta$-D-glucopyranoside, and 3, 4, 5-trimethoxyphenyl- $\beta$-Dglucopyranoside was not reported until now.

Therefore, the aim of this study is to develop the simultaneous analytical methods for phenolic compounds with various bioactivities such as antioxidant and antiosteoporosis activities and evaluate the contents of these compounds in maesil for good quality control.

\section{Materials and Methods}

2.1. Chemicals and Reagents. Compounds 1 and 5 as reference compounds for this study were obtained from Adooq Bioscience (Irvine, CA, USA) and Toronto Research Chemicals (Toronto, ON, Canada), respectively. And other seven reference standards (compounds 2, 3, 4, 6, 7, 8, and 9) were received from Prof. Young-Ho Kim (College of Pharmacy, Chungnam National University, Daejeon, Korea) in July 2014. The purity of all standards was over $95.6 \%$. The water used was ultrapure deionized water of $18 \mathrm{M} \Omega$ produced by the ultrapure water manufacturing device (Optimos SHRO-UP, Shinhan Science Tech, Daejeon, Korea). All other solvents used were of HPLC or highest grade available. The chemical structures of these reference compounds are shown in Figure 1.

2.2. Samples. Unripe maesil (fresh fruits, $5 \sim 10 \mathrm{~kg}$ per sample) for this study was directly purchased from the agrofishery market places in Korea during June-July, 2015 (Table 1). The ripe fruit of each sample was produced by natural ripening of $2 \sim 5 \mathrm{~kg}$ of fresh fruits for $3 \sim 4$ days at $27 \pm 3^{\circ} \mathrm{C}$ or some of them were directly collected by getting ripe fruits naturally matured after 80-90 days of flowering from the market. 100 150 g per each sample was freeze-dried by a lyophilizer (Eyela FDU-540, Tokyo Rikakikai, Tokyo, Japan).

2.3. Preparation of Samples. First, the freeze-dried samples were grinded and powdered by a grinder (Blender 7011G, Waring Commercial, Torrington, CT, USA), and then, these were filtered with the molecular sieve (No. 20). $0.5 \mathrm{~g}$ of each sample was weighed, and $10 \mathrm{~mL}$ of $50 \%$ methanol was added. Second, all samples were extracted by reflux for $30 \mathrm{~min}$ at $80^{\circ} \mathrm{C}$ and then centrifuged by a centrifuge (MF550, Hanil Science, Inchon, Korea) for $10 \mathrm{~min}$ at $3000 \mathrm{rpm}$. All supernatants were filtered by a syringe membrane filter (PVDF, $0.45 \mu \mathrm{m}$, SmartPor-II, Woonki Science, Seoul, Korea). Each sample was injected with $5 \mu \mathrm{L}$ of volume of samples, using an HPLC autosampler.

2.4. HPLC Analytical Condition. The HPLC analytical system for the quantization of compounds 1-9 in maesil was a ShimazduLC-20A system equipped with two LC-20AD pumps, a SPD-20A UV/Vis detector, a CTO-10ASvp column oven, and a Sil-20A autosampler linked to a Shimadzu LabSolutions software program (Ver. 1.25, Shimadzu, Kyoto, Japan). In order to optimize the simultaneous analytical method for quality control of compounds 19 in samples, the peak selectivity was tested by parameters as follows: the used columns were XDB-C18 (Zorbax Eclipse XDB-C18, $5 \mu \mathrm{m}$, $150 \mathrm{~mm} \times 2.1 \mathrm{~mm}$ (ID), Agilent, Santa Clara, CA, USA), C4 (Deltapak C4, $5 \mu \mathrm{m}, 150 \mathrm{~mm} \times 2.1 \mathrm{~mm}$ (ID), Waters, Milford, MA, USA), C8 (Optima Pak C8, $5 \mu \mathrm{m}$, $150 \mathrm{~mm} \times 2.1 \mathrm{~mm}$ (ID), Rs Tech, Daejeon, Korea), C18 (Optima Pak C18, $5 \mu \mathrm{m}, 250 \mathrm{~mm} \times 4.6 \mathrm{~mm}$ (ID), Rs Tech, Daejeon, Korea), Fusion-RP (Synergi, Fusion-RP, $4 \mu \mathrm{m}$, $150 \mathrm{~mm} \times 4.6 \mathrm{~mm}$ (ID), Phenomenex, Torrance, CA, USA), and Kinetex F5 (pentafluorophenyl (PFP), $150 \mathrm{~mm} \times 4.6 \mathrm{~mm}$ (I.D.), $2.6 \mu \mathrm{m}$, Phenomenex, Torrance, CA, USA) column. $\mathrm{pH}$ parameters were checked at $\mathrm{pH} \mathrm{2,} \mathrm{4,} \mathrm{6,} \mathrm{and} \mathrm{8.} \mathrm{And} \mathrm{the}$ concentration of phosphate buffer solution for the mobile phase was tested at 2,4 , and $8 \mathrm{mM}$ within having no damage of column by high buffer concentration. Column temperatures were estimated at $25,30,40,45,50$, and $60^{\circ} \mathrm{C}$. Each peak of compounds 19 on HPLC chromatograms was scanned in the range of 190 400 nm of wavelength (split $1.2 \mathrm{~nm}$ ). The best analytical condition for quality control of compounds 19 in samples was selected through the estimation of above parameters.

2.5. LC-MS/MS Analytical Conditions. Identification of compounds 1-9 in maesil were performed on a Shimazdu LCMS-8040 triple quadruple tandem mass spectrometry (Shimadzu, Kyoto, Japan) in negative and positive ESI interface modes. The identification of each compound was carried out on the Kinetex F5, 2.6 $\mu \mathrm{m}$ (PFP, $150 \mathrm{~mm} \times 4.6 \mathrm{~mm}$ (I.D.), Phenomenex, Torrance, CA, USA) column by the mobile phase consisted of (A) $0.1 \%$ formic acid in water and (B) methanol. The elution condition of this mobile phase was hold to $5 \%$ B for $5 \mathrm{~min}$, increased to $40 \% \mathrm{~B}$ for $70 \mathrm{~min}$, increased to $60 \% \mathrm{~B}$ for $25 \mathrm{~min}$, increased to $100 \%$ 


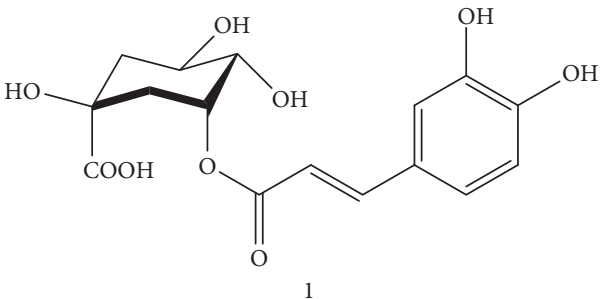

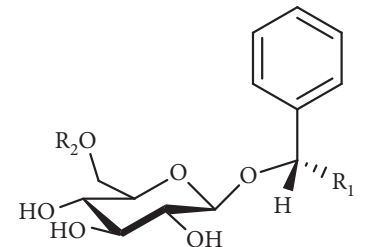<smiles></smiles>

$$
\begin{aligned}
& \text { 2: } \mathrm{R}_{1}=H, \mathrm{R}_{2}=\mathrm{H} \\
& \text { 4: } \mathrm{R}_{1}=\mathrm{CN}, \mathrm{R}_{2}=\mathrm{Glc} \\
& \text { 6: } \mathrm{R}_{1}=\mathrm{CN}, \mathrm{R}_{2}=\mathrm{H} \\
& \text { 7: } \mathrm{R}_{1}=\mathrm{H}, \mathrm{R}_{2}=\text { Ara-Pyr } \\
& \text { 8: } \mathrm{R}_{1}=\mathrm{H}, \mathrm{R}_{2}=\mathrm{Glc}
\end{aligned}
$$

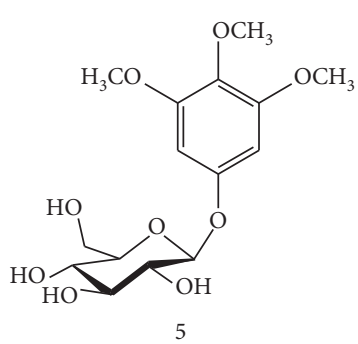<smiles>Oc1cc(O)c2c(c1)O[C@H](c1ccc(O)c(O)c1)[C@H](O)C2</smiles>

FIGURE 1: Structures of compounds 1-9 used as reference standards for $P$. mume fruits: 1 , neochlorogenic acid (NCA); 2 , benzyl- $\beta$-Dglucopyranoside (BGP); 3, $\beta$-D-glucopyranosyl benzoate (GPB); 4, amygdalin; 5, 3, 4, 5-trimethoxyphenyl- $\beta$-D-glucopyranoside (TMPGP); 6 , prunasin; 7 , benzyl- $\alpha$-L-arabinopyranosyl-( $\longrightarrow 6$ )- $\beta$-D-glucopyranoside (BAPGP); 8 , benzyl- $\beta$-D-xylopyranosyl-(1 $\longrightarrow 6)-\beta$-D-glucopyranoside (BXPGP); 9, (-)-epicatechin.

TABLE 1: Sample lists of P. mume fruits collected in Korea.

\begin{tabular}{lccc}
\hline Harvest regions* & No. of samples & \multicolumn{2}{c}{$\begin{array}{c}\text { Sample weight (average g/ } \\
\text { each fresh fruit) }\end{array}$} \\
& & Unripe fruits $^{\mathrm{a}}$ & Ripe fruits \\
\hline Daejeon & 1 & $12.96 \pm 5.69$ & $11.46 \pm 2.54$ \\
Gwangyang & 2 & $13.58 \pm 1.90$ & $12.17 \pm 0.40$ \\
Gyeryong & 4 & $17.12 \pm 7.82$ & $20.57 \pm 9.61$ \\
Gurye & 4 & $18.08 \pm 2.55$ & $17.36 \pm 2.52$ \\
Jangheung & 2 & $17.44 \pm 4.41$ & $18.33 \pm 4.32$ \\
Jinju & 4 & $20.33 \pm 2.66$ & $22.65 \pm 2.41$ \\
Nonsan & 2 & $20.75 \pm 3.28$ & $25.85 \pm 4.87$ \\
Sacheon & 1 & $10.84 \pm 2.97$ & $13.03 \pm 1.36$ \\
Suncheon & 1 & $17.70 \pm 1.84$ & $18.80 \pm 2.36$ \\
\hline
\end{tabular}

${ }^{*}$ All unripe and ripe fruits were collected from agrofishery markets. ${ }^{\mathrm{a}} \mathrm{An}$ unripe fruit is a fruit grown after 60-80 days of flowering. ${ }^{b}$ Ripe fruits were artificially produced by after-ripening of fresh fruits for $3 \sim 4$ days at $27 \pm 3^{\circ} \mathrm{C}$ or got ripe fruits naturally matured after $80-90$ days of flowering from the market.

B for $1 \mathrm{~min}$, hold to $100 \% \mathrm{~B}$ for $5 \mathrm{~min}$, decreased to $5 \% \mathrm{~B}$ for $1 \mathrm{~min}$, and then hold to maintain an enough equilibrium at $5 \% \mathrm{~B}$ for $13 \mathrm{~min}$, successively. Operation conditions of a mass detector were applied as follows: that is, capillary voltage, $3.5 \mathrm{kV} /-3.5 \mathrm{kV}$; desolation line (DL) temperature, $250^{\circ} \mathrm{C}$; heat block temperature, $350^{\circ} \mathrm{C}$; nebulizing gas $\left(\mathrm{N}_{2}\right)$ flow, $3 \mathrm{~L} / \mathrm{min}$; drying gas $\left(\mathrm{N}_{2}\right)$ flow, $15 \mathrm{~L} / \mathrm{min}$; and collision energy (CE) values for each reference compound were optimized by the multiple reaction monitoring (MRM) mode.

2.6. Method Validation. The validation of the developed method was estimated by following parameters based on guidelines of the MFDS (Ministry of Food and Drugs Safety of Korea): linearity, limits of detection (LODs), limits of quantitation (LOQs), precision, accuracy, and recovery. Compounds 19 were dissolved in $50 \%$ methanol to a final concentration of $500 \mu \mathrm{g} / \mathrm{mL}$ as stock solutions. And then, the prepared stock solutions were serially diluted with seven different concentrations with the range of $16 \sim 250 \mu \mathrm{g} / \mathrm{mL}$ (cf., compound 1, 16 500 $\mu \mathrm{g} / \mathrm{mL}$ ) to generate calibration curves of each compound. Linearity was evaluated by plotting the correlation coefficient $\left(r^{2}\right)$ with the integrated peak area of different standard concentrations. The evaluation method of LODs and LOQs was as follows: LODs were calculated based on the lowest detectable peak on the HPLC chromatogram containing signal-to-noise $(\mathrm{S} / \mathrm{N})$ ratio of 3 . LOQs were evaluated based on the lowest quantitative level on the HPLC chromatogram having signal-to-noise $(\mathrm{S} / \mathrm{N})$ ratio of 10. Precision and accuracy of intraday/interday were evaluated by analyzing five injections within a day for intraday and repeating five injections in a day during five consecutive days for interday at three different concentrations $(32,63$, and $93 \mu \mathrm{g} / \mathrm{mL})$. Precision was expressed as the 
relative standard deviations (\%RSD) of intraday/interday, and accuracy of intraday/interday was calculated as follows:

$$
\operatorname{accuracy}(\%)=\frac{\operatorname{conc}(\text { measured })}{\operatorname{conc}(\text { nominal })} \times 100,
$$

where conc (measured) is the measured concentration values of standards; and conc (nominal) is the nominal concentration values of standards.

Finally, the recovery test of marker compounds in samples was measured and calculated at three different concentration levels $(80 \%, 100 \%$, and $120 \%)$ of the contents for marker compounds in samples. The calculation of recovery ratio (\%) was as follows:

$$
\text { recovery }(\%)=\frac{\operatorname{conc}(\text { found })-\operatorname{conc}(\text { original })}{\text { conc }(\text { spiked })} \times 100 \text {, }
$$

where conc (found) is the founded concentration of marker compounds in samples; conc (original) is the original concentration of marker compounds in samples; and conc (spiked) is the spiked concentration of marker compounds in samples.

2.7. Statistical Analysis. All experiments were estimated in triplicates. All data were expressed by mean \pm SD. The results were determined by one-way analysis of variance (ANOVA) using IBM SPSS statistic software (Ver. 22, IBM Co., Armonk, New York, USA). The posteriori tests were evaluated by Turkey's method. The statistical significance level ( $p$ value) was set up at $p<0.05(95 \%)$

\section{Results and Discussion}

3.1. Optimization of HPLC Conditions. The HPLC analytical condition was optimized for the effective quantification of compounds 1-9 with antiosteoporosis and antioxidant activities in maesil. In order to select the best HPLC analytical condition of compounds $1-9$, it was considered to various parameters of mobile phase, such as various columns, different $\mathrm{pHs}$, and different buffer concentrations. In results, $\mathrm{pH}$ and buffer concentration of the best mobile phase were $\mathrm{pH} 4.0$ and $2 \mathrm{mM}$ sodium phosphate aqueous solution in combination with methanol-acetonitrile $(1: 1)$ mixture solution (Supplementary Figures S1, S3). And the highest UV absorption for these compounds was observed at UV $210 \mathrm{~nm}$. Also, the minimal peak tailing and high selectivity at a column temperature of $45^{\circ} \mathrm{C}$ were observed (Supplementary Figure S4). All standards in samples were clearly separated within $75 \mathrm{~min}$. Each peak of these compounds was identified with comparison of retention time $\left(t_{R}\right)$, and $\mathrm{UV}$ and MS spectra (Supplementary Table S1 and S2).

3.2. Identification of Compounds 1-9 by LC-MS/MS. All analysts were identified by the full scanning (scan range was 100 1000 a.m.u.) in both positive and negative modes using LC-ESI-MS. The different collision energy voltages $(-30 \sim 18 \mathrm{~V})$ were applied for characterizing these compounds
19 using full-scan mass spectra and multiple reaction monitoring (MRM) data, respectively (Supplementary Table S1). Compounds $1,4,5,6,7$, and 8 were observed in precursor ions on MS spectra and their product ions of MS/MS spectra in both positive and negative modes. In particular, for compounds 19, the MS/MS fragment intense ions were further fragmented by multiple reaction monitoring (MRM), which showed major fragment intense ions. Among them, compounds 1, 7, and 8 were further fragmented with two kinds of fragmentation pathways (pathway I and II) in both of ionization mode.

For compounds 5, 7, and 8 among nine compounds, the subfragmentation patterns of MS/MS for these compounds are newly showed as follows. The fragmentation pathway for compound 5 in positive mode showed four fragment intense peaks, that is, [M-161]+ at $m / z 185,[\mathrm{M}-193]+$ at $m / z 153$, [M-221]+ at $m / z 125$, and [M-303] + ion at $m / z$ 43. These ions were fragmented by the loss of the beta-D-glucopyranosyl group, water and methyl group, carbon monoxide group, and $\mathrm{CH} 3 \mathrm{CHCCOCH} 2$ - group from the precursor ion $([\mathrm{M}+\mathrm{H}]+, m / z 347)$ and its product ion, successively.

Compound 5 showed the fragmentation pathway with two fragment intense peaks as [M-H]- at $m / z=345$ and [M192] - at $\mathrm{m} / z=153$ by the elimination of formic acid, glucose, and the methyl group from the precursor ion $[\mathrm{M}+\mathrm{HCOO}]-$ at $\mathrm{m} / z 391$ in negative mode, successively.

For compounds 7 and 8, two compounds had same precursor ions such as $[\mathrm{M}+\mathrm{NH} 4]+$ at $\mathrm{m} / z \quad 420$ and $[\mathrm{M}+\mathrm{HCOO}]-$ at $\mathrm{m} / z 447$ in positive and negative modes. However, the fragment intense ion patterns of their product ions were different. Namely, compound 7 has five fragment intense ion patterns as [M-107]+ at $m / z 295,[\mathrm{M}-239]+$ at $m /$ $z$ 91, [M-305]+ at $m / z$ 97, and [M-329]+ at $m / z 73$ by the amine group and water and $\mathrm{HOCH} 2 \mathrm{CHOHCO}$ - group from the precursor ion, successively. In negative mode, compound 7 showed [M-H]- at $m / z 401,[M-133]-$ at $\mathrm{m} / z 269$, [M-271]- at $m / z 131$, and [M-301]- at $m / z 101$ by the loss of formic acid and the $a$-L-arabinopyranosyl group from the precursor ion successively.

While compound 8 showed different fragment ion patterns with [M-107]+ at $m / z 295$, [M-305]+ at $m / z$ 97, [M$329]+$ at $m / z 73$, and [M-345]+ at $m / z 57$ as the fragmentation pathway I and [M-311]+ at $m / z 91$ as pathway II from the precursor ion, respectively. And in negative mode, its product ions from the precursor ion showed five fragment intense ions as [M-H]- at $m / z 401$ by the elimination of formic acid from the precursor ion, and then, it became [M133]- at $m / z 269$ by the loss $a$-L-arabinosyl group, and [M133]- at $m / z 269$ had the two subfragmentation pathway as follows: one was [M-241]- at $m / z 161$ and the other was [M301]- at $m / z \quad 101$ and [M-343]- at $\mathrm{m} / z$ 59, respectively. Compounds 5, 7, and 8 were assigned with 3, 4, 5-trimethoxyphenyl- $\beta$-D-glucopyranoside (5, TMPGP), benzyl$\alpha$-L-arabinopyranosyl-(1 $\longrightarrow 6)$ - $\beta$-D-glucopyranoside $\quad(7$, BAPGP), and benzyl- $\beta$-D-xylopyranosyl- $(1 \longrightarrow 6)-\beta$-Dglucopyranoside ( 8, BXPGP) by comparing with the MS/MS data of reference standards, respectively. MS and MS/MS data of these compounds and their fragment pathways were reported in this study for the first time. Compounds 1, 2, 3, 4, 
TABLE 2: Summary of UV, MS, and MS/MS spectra for nine compounds obtained from P. mume fruits.

\begin{tabular}{|c|c|c|c|c|c|c|c|}
\hline No. & $\begin{array}{l}\text { Retention } \\
\text { time } \\
(\mathrm{min}) \\
\end{array}$ & $\begin{array}{c}\mathrm{UV} \\
\text { absorbance } \\
(\lambda \max , \mathrm{nm}) \\
\end{array}$ & $\begin{array}{l}\text { Molecular } \\
\text { formula }\end{array}$ & $\begin{array}{l}\text { Molecular } \\
\text { weight }\end{array}$ & $\begin{array}{l}\text { Precursor ion } \\
\qquad(\mathrm{m} / z)\end{array}$ & Product ion $(\mathrm{m} / z$, int., \%) & $\begin{array}{l}\text { Identified } \\
\text { name }\end{array}$ \\
\hline 1 & 27.3 & $217,233,324$ & $\mathrm{C}_{16} \mathrm{H}_{18} \mathrm{O}_{9}$ & 354 & $\begin{array}{l}{[\mathrm{M}+\mathrm{H}]^{+}(355)} \\
{[\mathrm{M}-\mathrm{H}]^{-}(353)}\end{array}$ & $\begin{array}{c}89(21.7), 117(13.0), 135(15.2) \\
145(21.7), 163(100.0) \\
85(2.4), 135(53.9), 173(2.6) \\
179(62.0), 191(100.0)\end{array}$ & NCA \\
\hline 2 & 33.3 & 258 & $\mathrm{C}_{13} \mathrm{H}_{18} \mathrm{O}_{6}$ & 270 & {$\left[\mathrm{M}+\mathrm{HCOO}^{-}(315)\right.$} & $269(21.2)$ & BGP \\
\hline 3 & 34.0 & 235 & $\mathrm{C}_{11} \mathrm{H}_{16} \mathrm{O}_{7}$ & 284 & {$[\mathrm{M}+\mathrm{Na}]^{+}(307)$} & $\begin{array}{l}24(2.6), 177(2.3), 194(52.3) \\
266(100.0)\end{array}$ & GPB \\
\hline 4 & 36.6 & 203,270 & $\mathrm{C}_{20} \mathrm{H}_{27} \mathrm{NO}_{11}$ & 457 & $\begin{array}{c}{\left[\mathrm{M}+\mathrm{NH}_{4}\right]^{+}(475)} \\
{[\mathrm{M}-\mathrm{H}]^{-}(356)} \\
\end{array}$ & $\begin{array}{c}69(70.6), 85(100.0), 145(41.0) \\
163(47.7), 325(56.8) \\
323(100.0) \\
\end{array}$ & Amygdalin \\
\hline 5 & 38.4 & 196,233 & $\mathrm{C}_{15} \mathrm{H}_{22} \mathrm{O}_{9}$ & 346 & $\begin{array}{c}{[\mathrm{M}+\mathrm{H}]^{+}(347)} \\
{[\mathrm{M}+\mathrm{HCOO}]^{-}(391)}\end{array}$ & $\begin{array}{c}43(1.1), 125(15.9), 153(31.7) \\
185(100.0) \\
153(23.0), 345(38.0)\end{array}$ & TMPGP \\
\hline 6 & 40.7 & 190,260 & $\mathrm{C}_{14} \mathrm{H}_{17} \mathrm{NO}_{6}$ & 295 & $\begin{array}{c}{\left[\mathrm{M}+\mathrm{NH}_{4}\right]^{+}(313)} \\
{[\mathrm{M}+\mathrm{HCOO}]^{-}} \\
(340) \\
\end{array}$ & $\begin{array}{c}231(55.0), 272(100.0) \\
161(100.0), 188(57.4), 294 \\
(55.3)\end{array}$ & Prunasin \\
\hline 7 & 41.1 & 202,277 & $\mathrm{C}_{16} \mathrm{H}_{18} \mathrm{O}_{9}$ & 402 & $\begin{array}{c}{\left[\mathrm{M}+\mathrm{NH}_{4}\right]^{+}(420)} \\
{[\mathrm{M}+\mathrm{HCOO}]^{-}(447)}\end{array}$ & $\begin{array}{c}73(83.5), 91(100.0), 97(52.2) \\
163(69.6), 295(78.3) \\
101(8.1), 131(4.3), 269(13.5) \\
401(100.0)\end{array}$ & BAPGP \\
\hline 8 & 52.1 & 210,244 & $\mathrm{C}_{16} \mathrm{H}_{18} \mathrm{O}_{9}$ & 402 & $\begin{array}{c}{\left[\mathrm{M}+\mathrm{NH}_{4}\right]^{+}(420)} \\
{[\mathrm{M}+\mathrm{HCOO}]^{-}(447)}\end{array}$ & $\begin{array}{c}57(30.0), 73(45.0), 91(100.0) \\
97(50.0), 295(70.0) \\
59(4.8), 101(14.3), 161(19.0) \\
269(59.5), 401(100.0)\end{array}$ & BXPGP \\
\hline 9 & 52.4 & 210,261 & $\mathrm{C}_{16} \mathrm{H}_{18} \mathrm{O}_{9}$ & 290 & {$[\mathrm{M}+\mathrm{H}]^{+}(291)$} & $\begin{array}{c}95(0.4), 123(46.3), 133(1.9) \\
139(100.0)\end{array}$ & (-)-Epicatechin \\
\hline
\end{tabular}

6, and 9 by comparing MS and MS/MS data of the reference standards and literatures were also assigned with neochlorogenic acid (1, NCA) [34], benzyl$\beta$-D-glucopyranoside (2, BGP) [35], $\beta$-D-glucopyranosyl benzoate (3, GPB) [36], amygdalin (4), prunasin (6) [37], and $(-)$-epicatechin $(9)[38,39]$, respectively. These without amygdalin were known with antiosteoporosis activity and antioxidants. But, amygdalin was known with cytotoxicity activity. The MS, MS/MS, and UV spectra for compounds 1-9 are summarized in Table 2. And the predicted fragmentation pathway for compounds 5,7 , and 8 among nine compounds is elucidated in Figure 2.

3.3. Optimization of Sample Preparation for Active Compounds in Maesil. To optimize the extraction condition of nine active compounds from maesil, the parameters such as species of extraction solvents, extraction time, and extraction method were estimated. In extraction effect comparison of various solvents as shown in Supplementary Figure S5, the content of active compounds in each solvent extract was different. That is, each content of compounds 1-4 in methanol extracts was $0.84 \pm 0.02,0.25 \pm 0.02,0.44 \pm 0.11$, and $0.06 \pm 0.01 \%$, which were the highest than those of three compounds in other solvent extracts. Also, in statistical analysis using a one-way ANOVA test, $p$ value for methanol extracts was shown as $p<0.05$, and it indicated that the content of other solvents was different. And, the content of compounds 3 and 8 in methanol extract was $0.25 \pm 0.02$ and $0.05 \pm 0.01 \%$, respectively. It was similar to those of two compounds in ethanol and water extracts. Also, the content of compounds 5 and 7 in methanol extracts was $0.01 \pm 0.00$ and $0.12 \pm 0.00 \%$, and it was similar with those of ethanol and water extracts from the analysis results of the one-way ANOVA test in the range of $95 \%$ confidence interval $(p<0.05)$. While the content of compounds 6 and 9 in methanol extracts was $0.00 \pm 0.00$ and $0.04 \pm 0.01 \%$, respectively. They were similar to the contents of these compounds in other solvents except for n-butanol and acetone extracts, and their results were not distinguished in statistical analysis using a one-way ANOVA as $p<0.05$. However, the total content of all active compounds in methanol extract was $1.82 \pm 0.02 \%$, and it was the highest than those of all active compounds in other solvent extracts. Also, it was distinguished to other solvent extracts in statistical analysis using a one-way ANOVA test. In the comparison of the extraction effectiveness by extraction solvents, the best extraction solvent for active compounds from mume fruit was verified as methanol.

On the other hand, in the comparison of extraction effectiveness by methanol-water ratio (water and $30 \%, 50 \%$, $70 \%$, and $100 \%$ methanol extracts) as shown in Supplementary Figure S6, the content of compounds 2, 4, and 6 in water solvent was $0.02 \pm 0.00 \%, 0.05 \pm 0.00 \%$, and $0.03 \pm 0.00 \%$, respectively, and it was different as $p<0.05$ in 
1. Compound 5

- MS/MS fragmentation pathways in positive ion mode
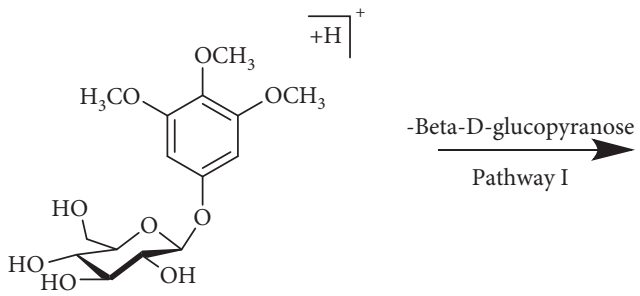<smiles>COC1=CC(O)CC(OC)=C1OC</smiles>

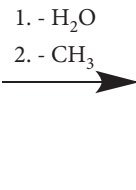

$\mathrm{m} / \mathrm{z}=185,[\mathrm{M}-161]^{+}$

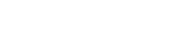

-MS/MS fragmentation pathways in negative ion mode

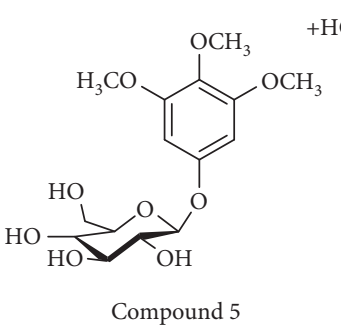

$\left(\mathrm{m} / \mathrm{z}=391,[\mathrm{M}+\mathrm{HCOO}]^{-}\right)$

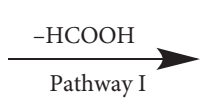

(1)<smiles>COc1cc(OC(O)C2COC(O)C(O)CC2O)cc(OC)c1OC</smiles>
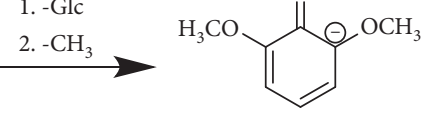

$\mathrm{m} / \mathrm{z}=153,[\mathrm{M}-192]^{-}$

\section{Compound 7}

-MS/MS fragmentation pathways in positive ion mode

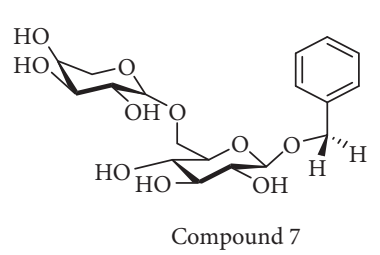

$\left(\mathrm{m} / \mathrm{z}=420,\left[\mathrm{M}+\mathrm{NH}_{4}\right]^{+}\right)$

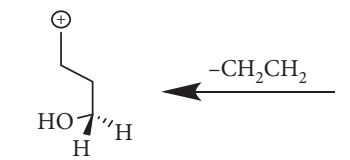

$\mathrm{m} / \mathrm{z}=73,[\mathrm{M}-329]^{+}$
$+\mathrm{NH}_{4}$
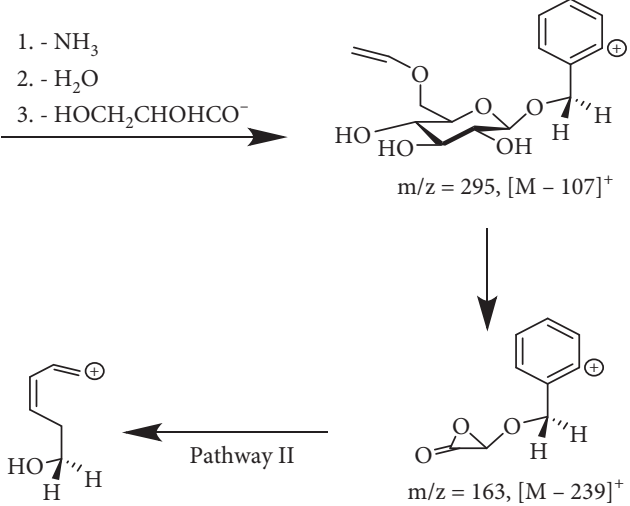

$\mathrm{m} / \mathrm{z}=97,[\mathrm{M}-305]^{+}$

(a)

FIgURE 2: Continued. 
-MS/MS fragmentation pathways in negative ion mode

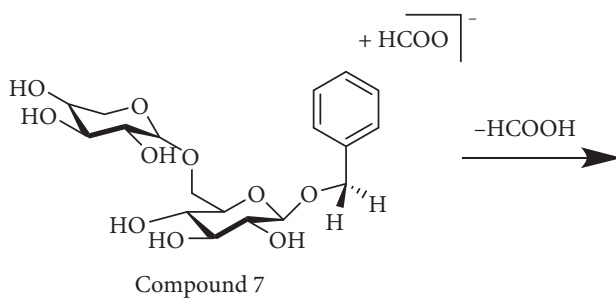

$\left(\mathrm{m} / \mathrm{z}=447,[\mathrm{M}+\mathrm{HCOO}]^{-}\right)$
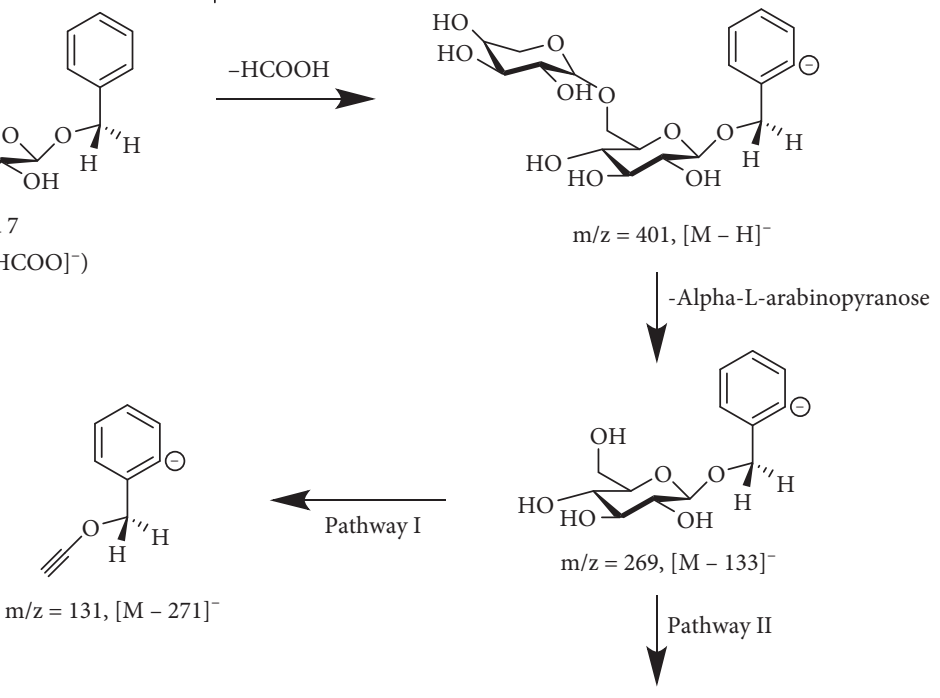

$\mathrm{m} / \mathrm{z}=131,[\mathrm{M}-271]$

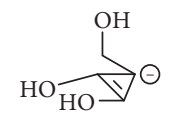

$\mathrm{m} / \mathrm{z}=101,[\mathrm{M}-301]$

\section{Compound 8}

-MS/MS fragmentation pathways in positive ion mode

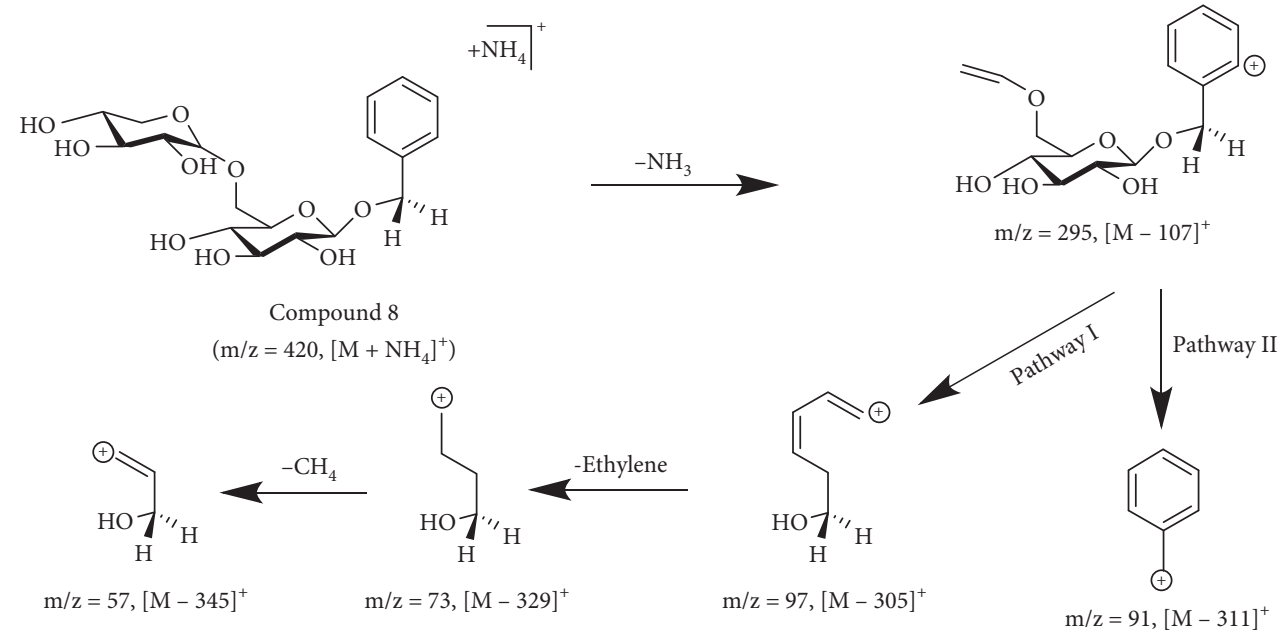

(b)

Figure 2: Continued. 
-MS/MS fragmentation pathways in negative ion mode

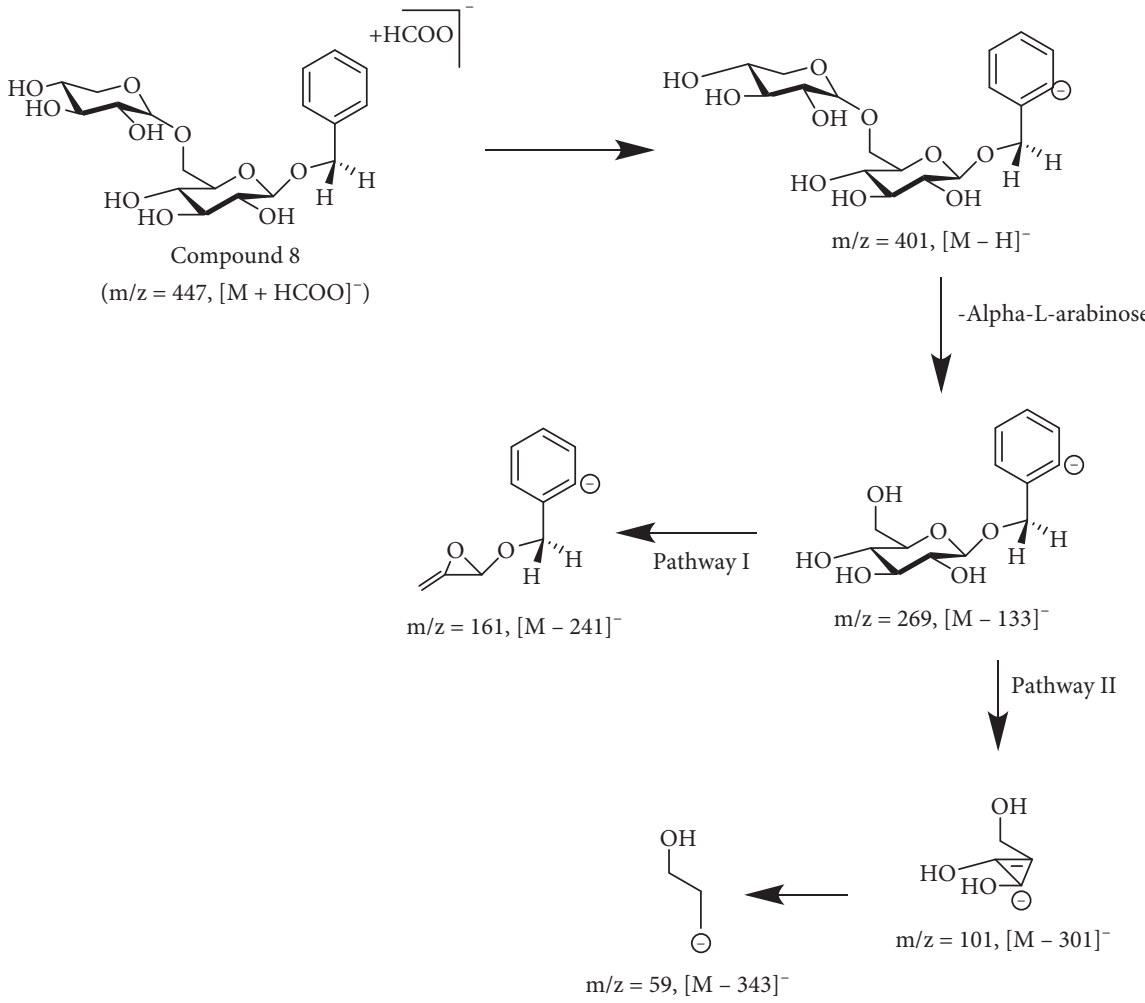

(c)

FIGURE 2: The predicted MS/MS fragmentation pathways of compounds 1-9 in positive and negative modes.

comparison of the content of compounds 1-9 among methanol-water solvent extracts by statistical analysis using a one-way ANOVA test. While the content of other compounds except for above three compounds in methanolwater solvent extracts was similar and was verified to be no significant as $p>0.05$ in a one-way ANOVA test. And the total content of compounds $1-9$ in 50\% methanol and $70 \%$ methanol extracts among methanol-water solvent extracts was higher than other solvent extracts, but it was not significant as $p>0.05$ in a one-way ANOVA test. However, compound 1 peak among compounds $1-9$ in $70 \%$ and $100 \%$ methanol solvents was shown as fronting or a part of broken peak.

Finally, in the comparison of the extraction effect by two extraction methods using the reflux and sonication as shown in Supplementary Figure S7, the total content of compounds 1-9 in the sonication extraction method was increased from $1.30 \pm 0.10 \%$ for $0 \mathrm{~min}$ to $1.61 \pm 0.17 \%$ for $30 \mathrm{~min}$, but it was quickly decreased to $0.77 \pm 0.06 \%$ for $60 \mathrm{~min}$, and that of each compound except for compound 2 was shown as a similar pattern for $30 \mathrm{~min}$ and $60 \mathrm{~min}$. However, the total content of these compounds in the reflux method was $1.87 \pm 0.0 \%$ higher than the sonication method, and it was similar from $15 \mathrm{~min}$ to $90 \mathrm{~min}$ except for $0 \mathrm{~min}$. Also, it was not significant as $p>0.05$ in the one-way ANOVA test.
When inclusively considering above results, the best condition to extract compounds $1-9$ in maesil was $50 \%$ methanol using the reflux method for $30 \mathrm{~min}$.

3.4. Method Validation of Active Compounds. The validation of the developed method was performed using the following parameters in accordance with guidelines of the MFDS [40-42]. That is, linearity, limit of detection (LOD), limit of quantitation (LOQ), precision, accuracy, and recovery. The results of each parameter are shown in Table 3. LOD and LOQ levels of each compound were $0.37 \sim 3.85 \mu \mathrm{g} / \mathrm{mL}$ and $1.24 \sim 12.82 \mu \mathrm{g} / \mathrm{mL}$, respectively. Range value of each standard was $16 \sim 250 \mu \mathrm{g} / \mathrm{mL}$ (compound 1, 16 500 $\mu \mathrm{g} / \mathrm{mL}$ ). Linearity ( $r^{2}$ value) was shown by passing the starting point as over 0.999 in all standards. Precision of intraday and interday of each compound was $0.0 \sim 3.9 \%$ and $0.1 \sim 3.0 \%$ at three different concentrations $(16.0,63.0$, and $250.0 \mu \mathrm{g} / \mathrm{mL})$, respectively. In addition, accuracy of intraday and interday was $98.8 \pm 2.1 \sim 101.9 \pm 0.9 \%$ and $98.6 \pm 1.8 \sim 109.2 \pm 3.4 \%$, respectively. Finally, the results of recovery tests as shown in Table 3 was $98.1 \sim 104.4 \%$ (RSD values were $0.3 \sim 5.2 \%$ ) at three different concentrations $(31.3,63.0$, and $125.0 \mu \mathrm{g} / \mathrm{mL})$, respectively. In results, all data of these parameters were satisfied with the criteria of the MFDS guidelines. 


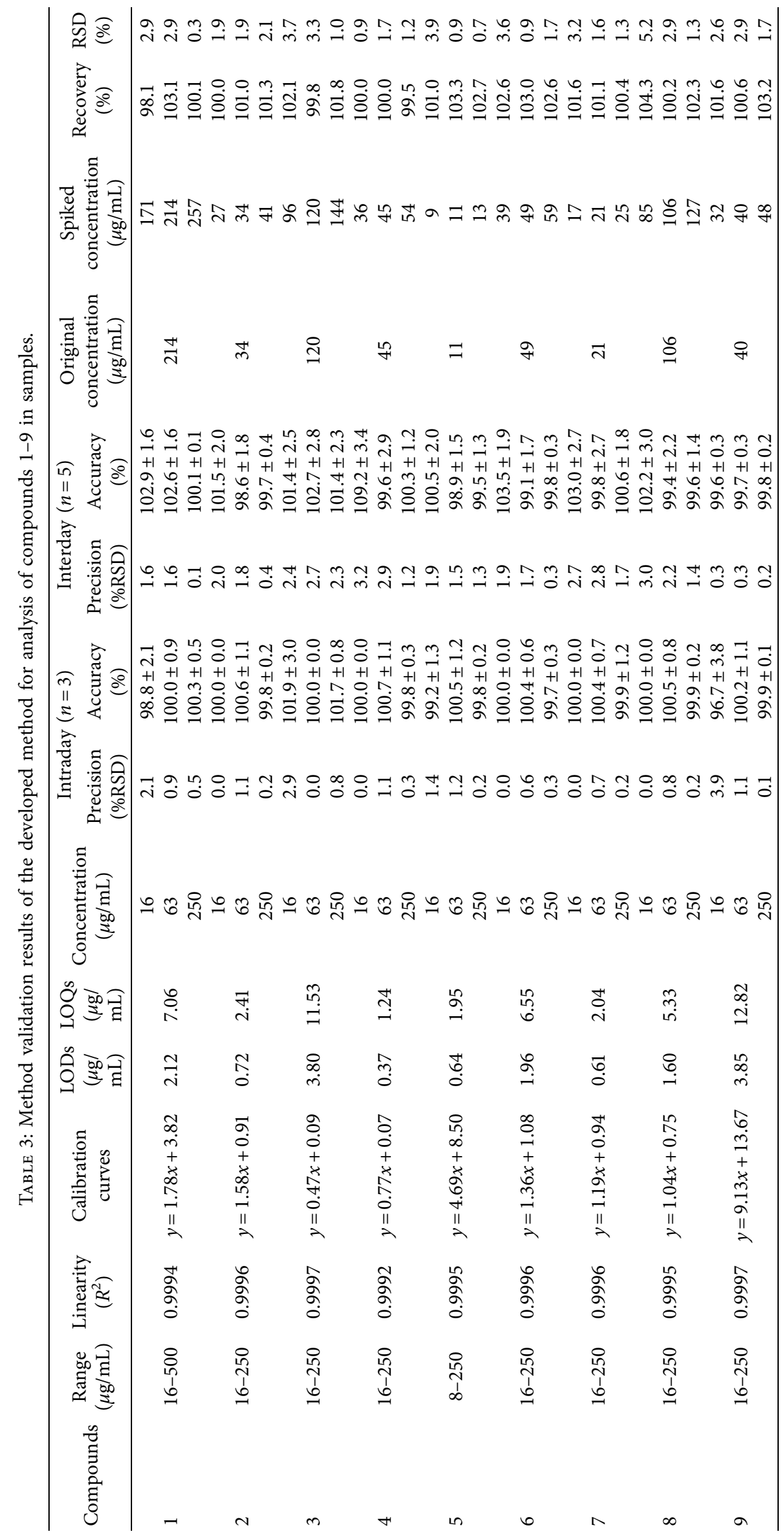


$\mathrm{mV}(\times 100)$

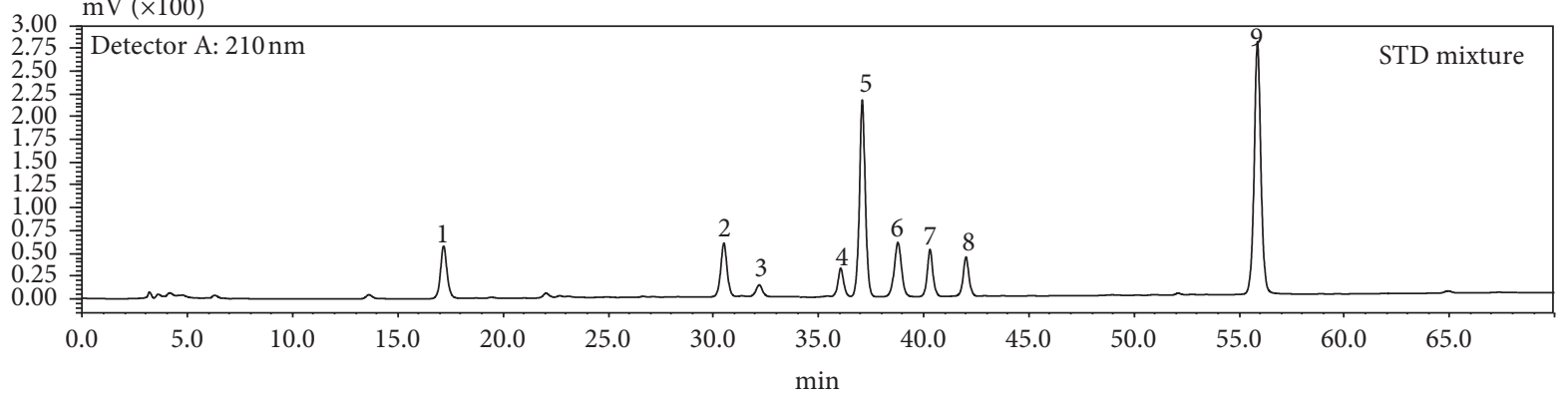

$\mathrm{mV}(\times 100)$
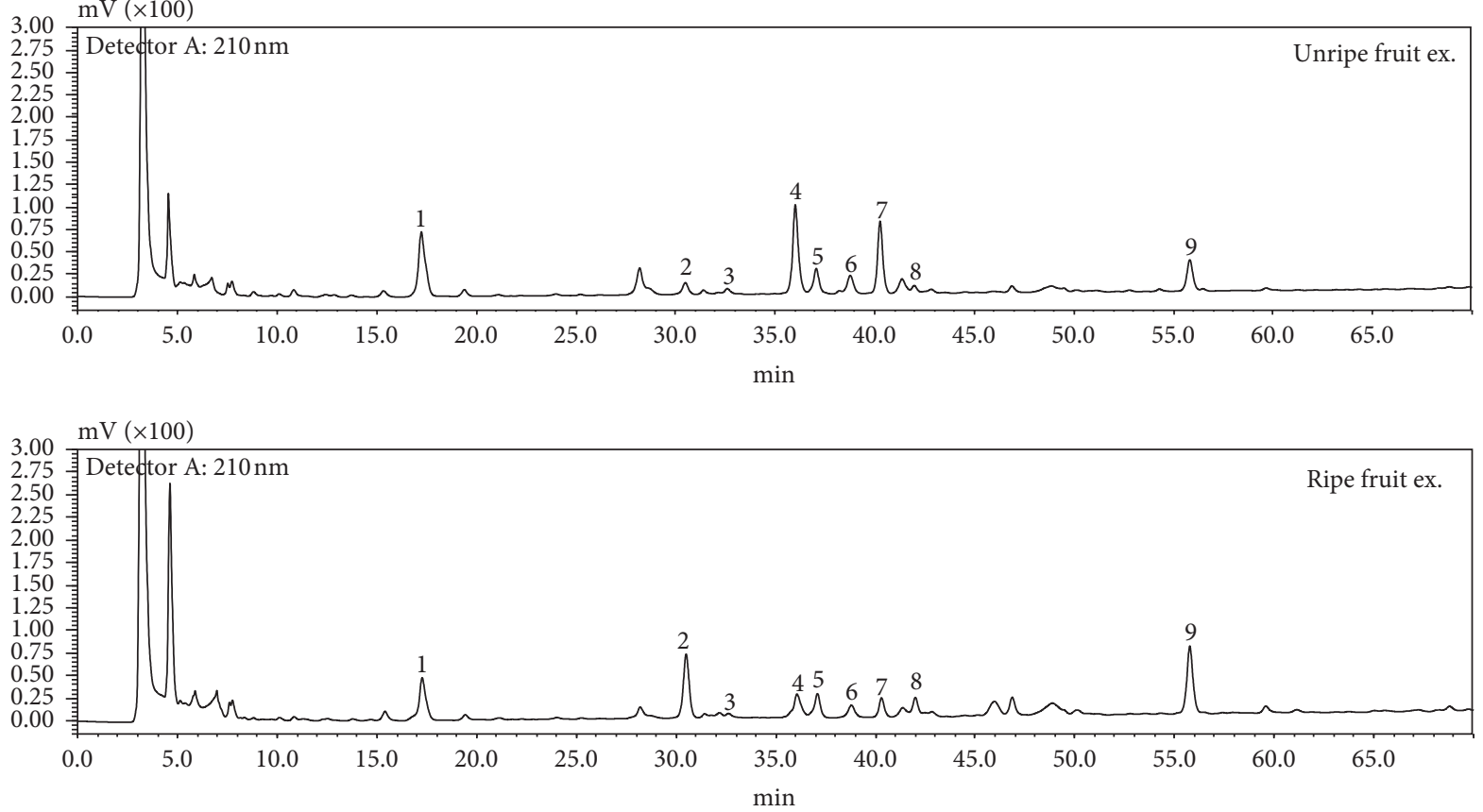

FIGURE 3: High-performance chromatograms of standard mixtures of compounds 1-9 in unripe and ripe P. mume fruits: 1, neochlorogenic acid (NCA); 2 , benzyl- $\beta$-D-glucopyranoside (BGP); 3, $\beta$-D-glucopyranosyl benzoate (GPB); 4 , amygdalin; 5 , 3, 4, 5 -trimethoxyphenyl- $\beta$-Dglucopyranoside (TMPGP); 6, prunasin; 7 , benzyl- $\alpha$-L-arabinopyranosyl-(1 $\longrightarrow 6$ )- $\beta$-D-glucopyranoside (BAPGP); 8 , benzyl- $\beta$-D-xylopyranosyl-(1 $\longrightarrow$ ) - $\beta$-D-glucopyranoside (BXPGP); 9, (-)-epicatechin).

TABle 4: The contents of compounds 1-9 in each part of the unripe and ripe P. mume fruits.

\begin{tabular}{|c|c|c|c|c|}
\hline \multirow{2}{*}{ Compounds } & \multirow{2}{*}{ Ripeness } & \multicolumn{3}{|c|}{ Content of marker compounds in each part of fruits $(\mathrm{mg} / \mathrm{g})$} \\
\hline & & Whole & Seed & Flesh \\
\hline \multirow[b]{2}{*}{1} & Unripe fruits & $0.79 \pm 0.23$ & $0.19 \pm 0.19$ & $0.47 \pm 0.26$ \\
\hline & Ripe fruits & $0.75 \pm 0.44$ & $0.17 \pm 0.19$ & $0.61 \pm 0.38$ \\
\hline \multirow[b]{2}{*}{2} & Unripe fruits & $1.18 \pm 0.35^{*}$ & $1.18 \pm 0.12^{*}$ & $0.57 \pm 0.24$ \\
\hline & Ripe fruits & $0.56 \pm 0.27$ & $0.27 \pm 0.12$ & $0.43 \pm 0.20$ \\
\hline \multirow{2}{*}{3} & Unripe fruits & $0.62 \pm 0.27$ & $0.28 \pm 0.20$ & $0.36 \pm 0.17$ \\
\hline & Ripe fruits & $0.59 \pm 0.35$ & $0.29 \pm 0.17$ & $0.38 \pm 0.25$ \\
\hline \multirow[b]{2}{*}{4} & Unripe fruits & $1.81 \pm 1.06$ & $1.09 \pm 0.64$ & $0.18 \pm 0.15$ \\
\hline & Ripe fruits & $1.66 \pm 1.29$ & $1.32 \pm 0.98^{*}$ & $0.11 \pm 0.09$ \\
\hline \multirow{2}{*}{5} & Unripe fruits & $0.16 \pm 0.09$ & $0.10 \pm 0.03$ & $0.06 \pm 0.05$ \\
\hline & Ripe fruits & $0.09 \pm 0.04$ & $0.09 \pm 0.03$ & $0.03 \pm 0.01$ \\
\hline \multirow{2}{*}{6} & Unripe fruits & $0.29 \pm 0.19$ & $0.32 \pm 0.26$ & $0.17 \pm 0.11$ \\
\hline & Ripe fruits & $0.22 \pm 0.08$ & $0.44 \pm 0.37$ & $0.17 \pm 0.07$ \\
\hline \multirow[b]{2}{*}{7} & Unripe fruits & $1.15 \pm 0.53$ & $0.42 \pm 0.46$ & $0.93 \pm 0.48$ \\
\hline & Ripe fruits & $1.38 \pm 0.57$ & $0.26 \pm 0.14$ & $0.84 \pm 0.20$ \\
\hline \multirow[b]{2}{*}{8} & & & $0.66 \pm 0.69$ & $0.47 \pm 0.24$ \\
\hline & Ripe fruits & $0.66 \pm 0.34$ & $0.50 \pm 0.36$ & $0.54 \pm 0.22$ \\
\hline \multirow{2}{*}{9} & Unripe fruits & $0.90 \pm 0.46$ & $0.94 \pm 0,18$ & $0.22 \pm 0.27$ \\
\hline & Ripe fruits & $0.68 \pm 0.37$ & $0.88 \pm 0.08$ & $0.18 \pm 0.10$ \\
\hline
\end{tabular}

All data were repeated with the triplet, nonpair $t$-test, significant at ${ }^{*} p<0.05$. 
3.5. Quantitation Analysis for Active Compounds in Unripe and Ripe Fruits. In order to compare the content change of compounds $1-9$ by the ripeness between unripe and ripe fruits, the quantitation for compounds 1-9 was carried out using a HPLC. Figure 3 shows typical HPLC chromatograms of compounds 1-9 in unripe and ripe fruits of maesil. The contents of these compounds 19 in whole of unripe fruits were at a range of $016 \sim 1.81 \mathrm{mg} / \mathrm{g}$ with species of marker compounds. However, in ripe fruits, contents of compounds 19 were at a range of $0.09 \sim 1.66 \mathrm{mg} / \mathrm{g}$. In comparison of the compounds 19 contents for each part of fruits, the contents of compounds 4 and 6 with cytotoxicity in seed part of unripe fruits were increased as 20.8 and $40.1 \%$ rather than in that of unripe fruits. Also, that of compound 2 in seed part of ripe fruits during ripeness of unripe fruits was relatively decreased higher than in fresh part of ripe fruits.

On the one hand, the contents of compounds 2, 5, 8, and 9 in both seed part of fruits were relatively higher than in flesh part. In contrast, those of compounds 1, 3, and 7 in flesh part of fruits were relatively higher than that in seed part (Table 4).

\section{Conclusion}

A simultaneous analytical method to analyze nine compound contents using HPLC to estimate effective sources and processing products of maesil related to antioxidant and antiosteoporosis activities successfully developed. The developed analytical method was estimated by validation parameters such as linearity, LODs, LOQs, precision, and accuracy of intraday and interday, and the recovery test was based on guidelines of MFDS. To check the change of nine compounds contents by ripeness between unripe and ripe maesil, the quantitation of compounds 1-9 was carried out using HPLC. Compounds 1-9 contents in ripe fruits were generally reduced rather than that in unripe fruits. While those of compounds 4 and 6 with cytotoxicity in seed part of ripe fruits were increased as $20.8 \%$ and $40.1 \%$ rather than in that of unripe fruits. Also, that of compound 2 in seed part of ripe fruits during ripeness of unripe fruits was relatively decreased higher than that in fresh part of ripe fruits. That is, all of these compounds in ripe fruits were reduced more than in unripe fruits. On the one hand, the contents of compounds $2,5,8$, and 9 in seed part of fruits were relatively higher than that in flesh part. In contrast, those of compounds 1, 3, and 7 in flesh part of fruits were relatively higher than that in seed part. Generally, the contents of compounds 19 in unripe fruits were higher than that in ripe fruits. However, the contents of compounds 1-9 in each part (seed and fresh) of fruits were different according to species of compounds. It indicates that the selection of harvesting time and process part of fruits as the source of foods and medicines are important.

\section{Data Availability}

Antioxidants and antiosteoporosis activites of main compounds used in this study were already reported with the articles by the co-author. The results of bioactivities in articles are available at doi 10.1007/s12272-014-0389-2, 10.1016/j.foodchem.2014.01.078, and 10.1016/ j.bmcl.2014.01.028.

\section{Disclosure}

Young Sik Park and Chong Woon Cho are the co-first authors.

\section{Conflicts of Interest}

The authors declare that there are no conflicts of interest.

\section{Authors' Contributions}

Young Sik Park and Chong Woon Cho contributed equally.

\section{Acknowledgments}

The authors are very grateful to Professor Young Ho Kim at Chungnam National University for providing reference standards in the experiment. This work was supported by the research fund of Chungnam National University.

\section{Supplementary Materials}

Data of both Tables S1 and S2 explain the contents of MS/MS and UV spectra to support the identification of compounds 1-9 in P. mume fruits. Figures S1, S2, S3, and S4 show the selectivity of compounds 1-9 under different conditions such as columns, eluent buffers, $\mathrm{pH}$, and column temperature for optimizing the simultaneous analytical method of compounds 1-9 in P. meme fruits. Figures S5, S6, and S7 descript the extraction condition for optimizing the extraction condition of compounds 1-9 from $P$. mume fruits by comparing different parameters such as extraction solvents, methanol-water ratio, and extraction methods. (Supplementary Materials)

\section{References}

[1] J.-N. Wu, Anillustrated Chinese Material Medica, Oxford University Press, Oxford, UK, 2005.

[2] C.-H. Jeong, G. N. Choi, J. H. Kim et al., "Invitro antioxidant properties and phenolic composition of Korean commercial vinegars," Korean Society of Food Science and Technology, vol. 18, no. 5, pp. 1258-1262, 2009.

[3] K.-S. Seo, C.-K. Huh, and Y.-D. Kim, "Comparison of antimicrobial andantioxidant activities of Prunusmume fruit in differentcultivars," Korean Journal of Food Preservation, vol. 15, no. 2, pp. 288-292, 2008.

[4] Y. Imahori, M. Takemura, and J. Bai, "Chilling-induced oxidative stress and antioxidant responses inmume (Prunusmume) fruit during low temperature storage," PostharvestBiology and Technology, vol. 49, pp. 54-60, 2008.

[5] J.-H. Yoon, D.-C. Yang, and W.-S. Song, "AntioxidativeactivityintheextractsofJapaneseapricot (Prunus mumeSieb.etZucc)," Korean Journal of Plant Resources, vol. 8, no. 3, pp. 188-193, 2005.

[6] H.-J. Park, M.-M. Kim, and Y.-H. Oh, "Effect of fruit extract of Prunusmume on the scavenging activity of reactive oxygen 
species and melanin production in B16F1 Cells," KoreanJournal of Life Science, vol. 22, pp. 936-942, 2012.

[7] J.-Y. Hwang, J.-W. Ham, and S.-H. Nam, "The antioxidant activity of maesil (Prunusmume)," Journal of Life Science, vol. 36, pp. 461-464, 2004.

[8] Y.-K. Bae and T.-B. Choe, "Antioxidant and cell activity using extracts of mume fructus," Korean Journal of Medicinal Crop Science, vol. 19, no. 5, pp. 388-394, 2011.

[9] J.-A. Lee, J.-H. Ko, B.-G. Jung et al., "Fermented Prunus mume with probiotics inhibits 7, 12-Dimethylbenz[a]anthracene and 12-O-tetradecanoyl phorbol-13-acetate induced skin carcinogenesis through alleviation of oxidative stress," Asian Pacific Journal of Cancer Prevention, vol. 14, no. 5, pp. 2973-2978, 2013.

[10] X.-T. Yan, W. Li, Y.-N. Sun et al., "Identification and biological evaluation of flavonoids from the fruits of Prunus mume," Bioorganic \& Medicinal Chemistry Letters, vol. 24, no. 5, pp. 1397-1402, 2014.

[11] H.-R. Lee, Y. Park, H. J. Kim et al., "Extract from Prunus mume Sieb. et Zucc. Fruit Prevents LPS-induced Homotypic Aggregation of Monocytic THP-1 Cells via Suppression of Nitric Oxide Production and NF- $\kappa$ B Activation," Journal of Life Science, vol. 25, no. 7, pp. 801-809, 2015.

[12] M.-S. Ko and J.-B. Yang, "Antimicrobial activities of extracts of Prunusmume by sugar," Korean JournalofFood Preservation, vol. 16, no. 5, pp. 759-764, 2009.

[13] M.-H. Ha, W.-P. Park, S.-C. Lee, H.-J. Heo, and S.-H. Cho, "Antimicrobial characteristic of methanoli cextracts from Prunusmune by products against food spoilage microorganisms," Korean JournalofFood Preservation, vol. 14, no. 2, pp. 183-187, 2007.

[14] M. Y. Choi, H. R. Won, and H. J. Park, "Antimicrobial activities of maesil (Prunusmume) extract," The Korean Journal of Community Living Science, vol. 15, no. 4, pp. 61-66, 2004.

[15] W.-P. Park, S.-C Lee, S.-Y. Kim, S.-G. Choi, H.-J. Heo, and S.-H. Cho, "Separation and identification of antimicrobial substances from Prunusmume extract," Korean Journal of Food Preservation, vol. 15, no. 6, pp. 878-883, 2008.

[16] S. Nakamura, K. Fujimoto, T. Matsumoto et al., "Acylated sucroses and acylated quinic acids analogs from the flower buds of Prunus mume and their inhibitory effect on melanogenesis," Phytochemistry, vol. 92, pp. 128-136, 2013.

[17] H. Utsunomiya, S. Takekoshi, N. Gato et al., "Fruit-juice concentrate of Asian plum inhibits growth signals of vascular smooth muscle cells induced by angiotensin II," Life Sciences, vol. 72, no. 6, pp. 659-667, 2002.

[18] Y.-J. Chung, C. Park, Y.-K. Jeong, and Y.-H. Choi, “Apoptosis induction by methanol extract of Prunus mume fruits in human leukemia U937 cells," Journal of Life Science, vol. 21, no. 8, pp. 1109-1119, 2011.

[19] K. M. Lee, J. Bang, B. Y. Kim et al., "Fructus mumealle viates chronic cerebral hypoperfusion-induced white matter and hippo campal damage via inhibition of inflammation and down regulation of TLR4 and p38MAPK signaling," $B M C$ Complementary Medicine and Therapies, vol. 15, p. 125.

[20] M.-S. Kim, J. H. Bang, J. Lee, J.-S. Han, H. W. Kang, and W. K. Jeon, "Fructus mume ethanol extract prevents inflammation and normalizes the septohippocampal cholinergic system in a rat model of chronic cerebral hypoperfusion," Journal of Medicinal Food, vol. 19, no. 2, pp. 196-204, 2016.

[21] M. Adachi, Y. Suzuki, T. Mizuta et al., "The "Prunus mume Sieb. et Zucc" (Ume) is a Rich Natural Source of Novel AntiCancer Substance," International Journal of Food Properties, vol. 10, no. 2, pp. 375-384, 2007.
[22] J.-C. Park, J. Ma, W. K. Jeon, and J.-S. Han, "Fructus mume extracts alleviate cognitive impairments in 5XFAD transgenic mice," BMC Complementary and Alternative Medicine, vol. 16, no. 1, p. 54, 2016.

[23] I.-H. Kim, J.-B. Kim, K.-J. Cho, J.-H. Kim, and A.-S. Om, "Cytoprotective Effect of Ethanol Extract from Maesil (Prunus mume Sieb. et Zucc.) on Alloxan-induced Oxidative Damage in Pancreatic-cell, HIT-T15," Korean Journal of Plant Resources, vol. 25, no. 2, pp. 184-192, 2012.

[24] H.-J. Sheo, E.-Y. Ko, and M.-Y. Lee, "Effects of Prunus mume extract on experimentally alloxan induced diabetes in rabbits," Journal of the Korean Society of Food Science and Nutrition, vol. 16, no. 3, pp. 41-47, 1987.

[25] E. J. Shin, H. J. Hur, M. J. Sung et al., "Ethanol extract of the Prunus mume fruits stimulates glucose uptake by regulating PPAR- $\gamma$ in C2C12 myotubes and ameliorates glucose intolerance and fat accumulation in mice fed a high-fat diet," Food Chemistry, vol. 141, no. 4, pp. 4115-4121, 2013.

[26] Y. N. Youn, E. Lim, N. Lee, Y. S. Kim, M. S. Koo, and S. Y. Choi, "Screening of Korean medicinal plants for possible osteoclastogenesis effects in vitro," Genes \& Nutrition, vol. 2, no. 4, pp. 375-380, 2008.

[27] X.-T. Yan, S.-H. Lee, W. Li et al., "Evaluation of the antioxidant and anti-osteoporosis activities of chemical constituents of the fruits of Prunus mume," Food Chemistry, vol. 156, pp. 408-415, 2014.

[28] Z.-Y. Chen, Y.-S. Lin, X.-M. Liu, J.-R. Cheng, and C.-Y. Yang, "Chemical composition and antioxidant activities of five samples of Prunus mume Umezu from different factories in south and east China," Journal of Food Quality, vol. 2017, Article ID 4878926, 7 pages, 2017.

[29] M. Miyazawa, N. Shirakawa, H. Utsunomiya, K.-i. Inada, and T. Yamada, "Comparision of the volatile components of unripe and ripe Japanese apricot (Prunus mumeSieb. et Zucc.)," Natural Product Research, vol. 23, no. 17, pp. 1567-1571, 2009.

[30] T. Mitani, K. Ota, N. Inaba, K. Kishida, and H. A. Koyama, "Antimicrobial activity of the phenolic compounds of Prunus mume against enterobacteria," Biological and Pharmaceutical Bulletin, vol. 41, no. 2, pp. 208-212, 2018.

[31] Q. Jin, C. Lee, J. W. Lee et al., "Chemical constituents from the fruits of Prunus mume," Natural Product Sciences, vol. 18, no. 3, pp. 200-203, 2012.

[32] T. Mitani, A. Horinishi, K. Kishida et al., "Phenolics Profile of Mume, Japanese Apricot (Prunus mumeSieb. et Zucc.) Fruit," Bioscience, Biotechnology, and Biochemistry, vol. 77, no. 8, pp. 1623-627, 2013.

[33] O.-K. Lee, H.-J. Lee, Y.-S. Shin et al., "Quantitative analysis of the fruit flesh of Prunus mume Siebold \& Zuccarni," TheKorean JournalofCrop Science, vol. 15, no. 3, pp. 143-147, 2007.

[34] N. Fang, S. Yu, and R. L. Prior, "LC/MS/MS characterization of phenolic constituents in dried plums," Journal of Agricultural and Food Chemistry, vol. 50, no. 12, pp. 3579-3585, 2002.

[35] C. Jia, Y. Zhu, J. Zhang, J. Yang, C. Xu, and D. Mao, "Identification of glycoside compounds from tobacco by high performance liquid chromatography/electrospray ionization linear ion-trap tandem mass spectrometry coupled with electrospray ionization orbitrap mass spectrometry," Journal of the Brazilian Chemical Society, vol. 28, no. 4, pp. 629-640, 2017.

[36] S.-L. Li, J.-Z. Song, F. F. K. Choi et al., "Chemical profiling of Radix Paeoniae evaluated by ultra-performance liquid 
chromatography/photo-diode-array/quadrupole time-offlight mass spectrometry," Journal of Pharmaceutical and Biomedical Analysis, vol. 49, no. 2, pp. 253-266, 2009.

[37] X.-b. Li, C.-h. Liu, R. Zhang et al., "Determination and pharmacokinetics of amygdalin in rats by LC-MS-MS," Journal of Chromatographic Science, vol. 52, no. 6, pp. 476481,2014

[38] Q.-H. Zhang, W.-B. Wang, J. Li et al., "Simultaneous determination of catechin, epicatechin and epicatechin gallate in rat plasma by LC-ESI-MS/MS for pharmacokinetic studies after oral administration of Cynomorium songaricum extract," Journal of Chromatography B, vol. 880, pp. 168-171, 2012.

[39] C.-L. Chang and R.-T. Wu, "Quantification of (+)-catechin and (-)-epicatechin in coconut water by LC-MS," Food Chemistry, vol. 126, no. 2, pp. 710-717, 2011.

[40] Ministry of Food and Drug Safety, The Handbook of the Guideline of Method Validation for Medicines, Ministry of Food and Drug Safety, Cheongju, Korea, 2012.

[41] Ministry of Food and Drug Safety, The Guideline of Method Validation for Medicines, Ministry of Food and Drug Safety, Cheongju, Korea, 2015.

[42] Ministry of Food and Drug Safety, The Guideline for Setting the Component Profiling of Herbal Medicines (Formulations), Ministry of Food and Drug Safety, Cheongju, Korea, 2016. 